\title{
Continuous measurements of near surface aerosols in the south-western European (Portugal) region in 2006-2008
}

\author{
S. N. Pereira ${ }^{1}$, F. Wagner $^{1}$, and A. M. Silva ${ }^{1,2}$ \\ ${ }^{1}$ Évora Geophysics Centre, Évora, Portugal \\ ${ }^{2}$ University of Évora Physics Departement, Évora, Portugal
}

Received: 31 December 2008 - Revised: 8 March 2009 - Accepted: 13 March 2009 - Published: 1 April 2009

\begin{abstract}
Scattering and absorption coefficients near the ground were measured in Évora, Portugal, in the period of 2006 to 2008. The average scattering coefficient, at the wavelength of $550 \mathrm{~nm}$, for the whole period of measurements was found to be $40.3 \mathrm{Mm}^{-1}$ and the absorption coefficient, at the wavelength of $670 \mathrm{~nm}$, $8.6 \mathrm{Mm}^{-1}$. These values are comparable to those measured in rural or background locations and reflect the small size of the city and relatively low magnitude of anthropogenic production at the site. A marked seasonal variation was found for the absorption coefficient, with a significant increase from $5.8 \mathrm{Mm}^{-1}$, in summer, to $13.4 \mathrm{Mm}^{-1}$, in winter. Regarding black carbon mass concentrations, this twofold increase, from 0.9 to $2.0 \mu \mathrm{gm}^{-3}$, is mainly attributed to the wood combustion used for heating in conjunction with lower boundary layer mixing heights. The average scattering coefficient presented a more complex behaviour, although with a tendency for higher values in winter and lower values in spring.
\end{abstract}

\section{Introduction}

Aerosol particles in the atmosphere are known to interact with both the solar and the terrestrial radiation, via scattering and absorption processes (direct effect), and to modify the properties of clouds (indirect effect). Also there is the semi-direct aerosol effect on clouds, the process by which aerosol particles absorb incoming sunlight and warm enough the middle troposphere to reduce the cloud condensation formation potential (Koren et al., 2004). Moreover, air quality is highly influenced by the changing levels and composition of atmospheric particles.

The study is made at Évora $\left(38.5^{\circ} \mathrm{N}, 7.9^{\circ} \mathrm{W}, 300 \mathrm{~m}\right.$ a.s.1.), a small city ( $\sim 60000$ inhabitants), located within a rural region, and without significant industries. Therefore the local anthropogenic aerosol sources are basically due to vehicle related emissions and domestic heating by wood combustion. Agricultural and construction related works may also contribute to the particle load. Agricultural combustion doesn't play a role in this area. Major deviations from the typical background values were observed to be mainly related to

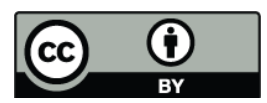

Correspondence to: S. N. Pereira

(sergiopereira@uevora.pt) desert dust from the Sahara region and forest fire or anthropogenic pollution aerosols transported to the site (Elias et al., 2006; Pereira et al., 2008).

This paper describes the magnitude and variability of aerosol climate relevant properties, at the surface, namely light scattering and absorption coefficients by in situ measurements of these quantities made between 2006 and 2008.

\section{Measurements and methodology}

The measurements cover the period from January 2006 to December 2008. An integrated Nephelometer (TSI Model $3563)$ measured the scattering coefficient, $\sigma_{\text {scatt }}(\lambda)$, at the wavelengths of 450,550 and $700 \mathrm{~nm}$, with $5 \mathrm{~min}$ resolution (in units of $\mathrm{Mm}^{-1}=10^{-6} \mathrm{~m}$ ); the measurements were corrected for the truncation of near-forward scattered light and the non-Lambertian illumination intensity of the instrument according to (Anderson and Ogren, 1998). The instrument was calibrated three times, once per year, using dry filtered air and $\mathrm{CO}_{2}$. A Multi-Angle Absorption Photometer (MAAP, Model 5012) measured the absorption coefficient at the single wavelength of $670 \mathrm{~nm}, \sigma_{\text {abs }}(670)$, with 1 min resolution; the instrument operated for two weeks, in June 2006, during the CAPEX campaign (Silva et al., 2007), and then on

Published by Copernicus Publications. 


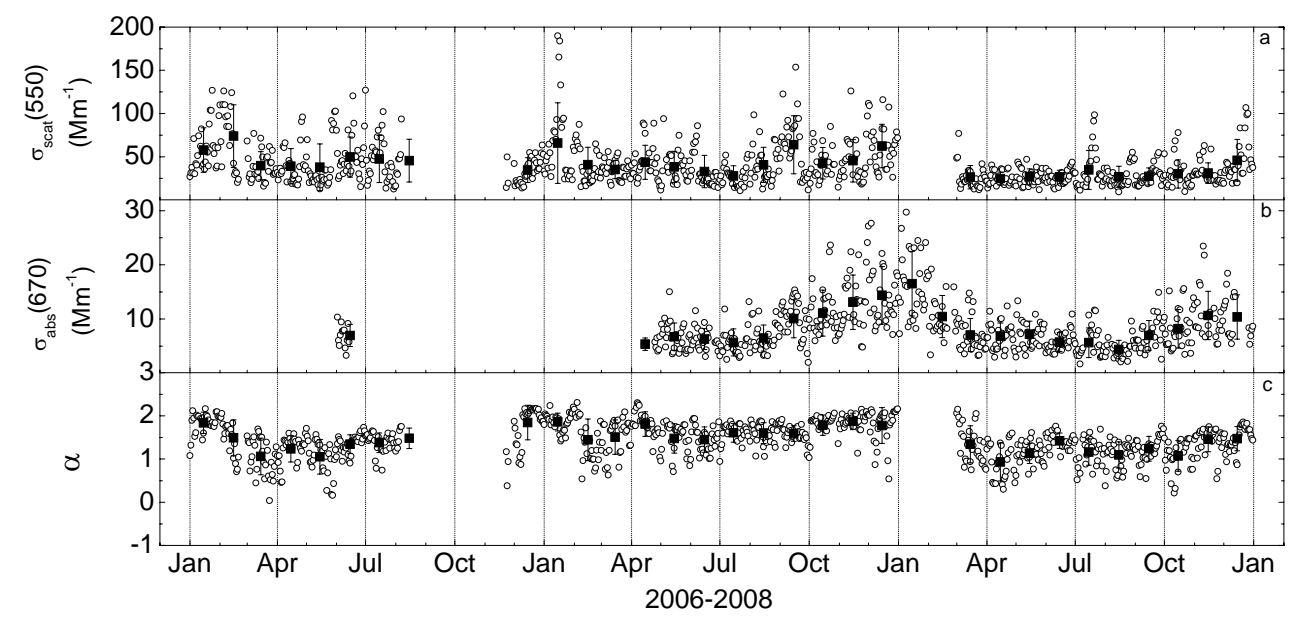

Figure 1. Temporal evolution of (a) $\sigma_{\text {scatt }}(550)$, (b) $\sigma_{\text {abs }}(670)$ and (c) $\alpha$ for the period of 2006 to 2008 . Monthly averages ( \pm one standard deviation) are also shown as full squares, located in the middle of the respective month.

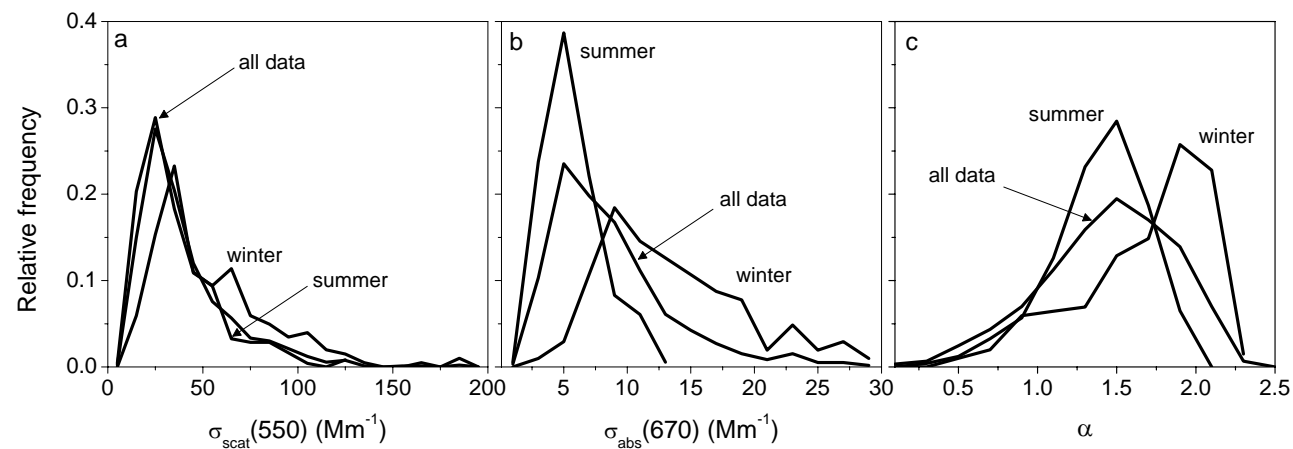

Figure 2. Relative frequency distribution of (a) $\sigma_{\text {scatt }}(550)$, (b) $\sigma_{\text {abs }}(670)$ and (c) $\alpha$ for winter and summer periods as well as for the whole dataset.

a regular basis since April 2007. Both instruments were provided with $\mathrm{PM}_{10}$ size cut inlets, sampling at about $10 \mathrm{~m}$ above ground.

The scattering Ångström exponent, $\alpha$, was derived from the scattering coefficients in the $450-700 \mathrm{~nm}$ wavelength range. It characterizes the wavelength dependence of $\sigma_{\text {scatt }}(\lambda)$ assuming a power law relationship, and indicates the relative importance of fine and coarse particles.

The black carbon mass concentration, $\mathrm{BC}$, was also derived, for convenience of the reader's to compare it with $\mathrm{BC}$ measured in other sites; it is proportional to the $\sigma_{\text {abs }}(670)$ (we used for the mass absorption efficiency a value of $6.6 \mathrm{~m}^{2} \mathrm{~g}^{-1}$, as indicated by the manufacturer).

Daily averaged values (from 00:00 to 24:00 UTC) were calculated and are used here to describe the magnitude and variability of the quantities pointed out in the previous section. The daily values were used for calculating monthly and seasonal averages: summer (JJA), spring (MAM) winter (DJF) and fall (SON).

\section{Results and discussion}

Figure 1 shows the temporal evolution of $\sigma_{\text {scatt }}(550)$, $\sigma_{\text {abs }}(670)$ and $\alpha$, and Fig. 2 shows the respective relative frequency distributions for the period from 2006 to 2008. In particular, taking into consideration the frequency distributions in Fig. $2 b$, the background conditions of $\sigma_{\text {abs }}(670)$ for summer and winter are clearly different, with the distributions being considerably detached from each other; the most frequently observed daily values of $\sigma_{\text {abs }}(670)$ increased noticeably during winter, to values close or above $10 \mathrm{Mm}^{-1}$, while in summer they rarely over passed $8 \mathrm{Mm}^{-1}$. Similar data collected during CAPEX, in June 2006, although limited in time, is comparable and adds confidence to this scheme. The average values of $\sigma_{\text {abs }}(670)$ for summer and spring were relatively constant, about $6-7 \mathrm{Mm}^{-1}$ (with monthly values in the range of 4.4 to $7.2 \mathrm{Mm}^{-1}$ ), and increased to 10.0 and $13.4 \mathrm{Mm}^{-1}$ in fall and winter respectively. The differences are statistically significant at 0.05 level. This is consistent with the idea of a stable anthropogenic activity (mostly 
traffic) along the year, complemented in the colder period by wood burning aerosols. Considering the whole period of measurements, the average value of $\sigma_{\text {abs }}(670)$ was found to be $8.6 \mathrm{Mm}^{-1}$ (with daily values ranging from 2 to $30 \mathrm{Mm}^{-1}$ ) with the median value of $\sigma_{\text {abs }}(670)$ being somewhat lower $\left(7.6 \mathrm{Mm}^{-1}\right)$ as expected by its right skewed distribution. The main source of absorbing particles influencing the site is the local traffic, which is continuous and relatively constant along the year, besides the episodic transportation of forest fires aerosols and urban/industrial aerosols from Iberian Peninsula and central Europe (Ansmann et al., 2002; Silve et al., 2002); domestic heating, mostly by wood burning, is the main additional anthropogenic source during the autumn and winter colder periods. These facts, plus the decrease in the boundary layer mixing heights, that inhibit the dispersion of pollutants, are likely the reasons for the enhancement on $\sigma_{\text {abs }}(670)$, both in magnitude and variability, observed during fall and winter when compared to spring and summer (warmer periods).

A more complex behaviour was observed for the aerosol scattering coefficients; higher variability was observed along the year, although with a tendency for lower scattering coefficients in spring and higher scattering coefficients in winter. In summer, the long range transport of Saharan dust and smoke from forest fires (the latter typically in the period of June to September) are customarily responsible for important increases in the aerosol load and therefore in the scattering coefficients (Elias et al., 2006). This was observed in 2006 (Pereira et al., 2008), but not in 2007 and 2008; forest fires were nearly absent until September 2007 and in 2008 there was no fire season at all; although the frequency of occurrence of desert dust events was similar for all 3 years the intensity of these events was lower in 2008. Additionally in 2008 the rainy season lasted longer and the summer was unusually wet. Therefore reduced erosion in the region of Évora due to a wet surface and particles wash out during rain events also contributed to the low particle concentrations observed in summer 2008 by the nephelometer at the surface. This explains the systematically lower values of $\sigma_{\text {scatt }}(550)$, and with less variability, during 2008 (annual average of $30 \mathrm{Mm}^{-1}$ ), when compared with the previous years (annual averages of 45 and $46 \mathrm{Mm}^{-1}$ ). The average value of $\sigma_{\text {scatt }}(550)$ for the whole period of measurements was found to be $40.3 \mathrm{Mm}^{-1}$ (with daily values ranging from 9 to $190 \mathrm{Mm}^{-1}$ ) with median value of $33 \mathrm{Mm}^{-1}$.

The values of $\alpha$ were generally high for the whole period under analysis ( $\alpha>1$ on $85 \%$ of the cases) with average and median values close to 1.5 , indicating that small particles (smaller than about $1 \mu \mathrm{m}$ ) generally dominated the aerosol population, but this relative abundance of small particles is even more evident during winter (average and median of 1.7 and 1.8 respectively ).

We now compare our results with the ones reported by other authors, focusing in Europe. Putaud et al., 2003 reviewed $\mathrm{BC}$ measurements made over various types of loca- tions; in natural background and rural sites the average values were in the range of 0.2 to $0.5 \mu \mathrm{g} \mathrm{m}^{-3}$ (with one exception) and presented no seasonal variations. In near city and urban background locations the increase in $\mathrm{BC}$ was evident (in the range of 1.4 to $2.9 \mu \mathrm{g} \mathrm{m}^{-3}$ ) and a seasonal variation was observed, with higher values in fall and winter than in spring and summer. In kerbsides $\mathrm{BC}$ values were even higher. Lyamani and Alados-Arboledas (2007) measured $\sigma_{\text {abs }}(670)$, in an urban area, and obtained average values of 16 and $28 \mathrm{Mm}^{-1}$ (about 2.4 and $4.2 \mu \mathrm{g} \mathrm{m}^{-3}$ in terms of BC) for summer and winter periods, respectively. In this study average value of $\sigma_{\text {abs }}(670)$ was found to be $8.6 \mathrm{Mm}^{-1}\left(1.3 \mu \mathrm{g} \mathrm{m}^{-3}\right.$ of BC) with summer and winter average values of 5.8 and $13.4 \mathrm{Mm}^{-1}$ respectively ( 0.9 and $2.0 \mu \mathrm{g} \mathrm{m}^{-3}$ of $\mathrm{BC}$ ). Hence the seasonal variation of $\mathrm{BC}$ that characterizes urban environments is also present in Évora, however with the average values of lower magnitude. The average value of $\sigma_{\text {scatt }}(550 \mathrm{~nm})$, $40.3 \mathrm{Mm}^{-1}$, found for the entire measurement period available is comparable to the ones obtained by Vrekoussis et al. (2005) in remote areas in Greece and Turkey $\left(50 \mathrm{Mm}^{-1}\right.$ and $45 \mathrm{Mm}^{-1}$, respectively). Gerasopoulos et al. (2003) reported a mean scattering coefficient of $65 \mathrm{Mm}^{-1}$ in northern Greece mainly related with continental pollution and Derimian et al. (2006) reported a long term average of $60 \mathrm{Mm}^{-1}$ at Sede Boker site, Israel. The average values of $\sigma_{\text {scatt }}(550 \mathrm{~nm})$ obtained by Lyamani and Alados-Arboledas (2007), 52 and $83 \mathrm{Mm}^{-1}$ for summer and winter periods, are, once more, significantly higher than our measurements $\left(36\right.$ and $\left.54 \mathrm{Mm}^{-1}\right)$.

\section{Conclusions}

Scattering and absorption coefficients were measured near the ground, in Évora, Portugal, during the period of 2006 to 2008. Both quantities were found to be, in general, of low magnitude and relatively closer to sites of rural and background characteristics than to large urban sites, reflecting the small size of the city where the measurements were made, in terms of population and anthropogenic aerosol production. However, the absorption coefficient presented an annual cycle typical for urban sites; this cycle is characterized by an increase of the absorption coefficient during the colder period, likely related to the increase of soot from wood combustion for domestic heating, absent during the warmer period, as well as traffic, in a context of lower boundary layer mixing heights that tend to reduce the dispersion of pollutants. The scattering coefficient's cycle was less clear because its variations can be related to a wider variety of aerosol types and to those aerosols that are transported to the site from different regions.

Acknowledgements. This work is supported by Fundação para a Ciência e a Tecnologia under the grant SFRH/BD/29008/2006.

Edited by: A. Baklanov

Reviewed by: two anonymous referees 


\section{References}

Anderson, T. L. and Ogren, J. A.: Determining aerosol radiative properties using the TSI 3563 integrating Nephelometer, Aerosol Sci. Technol., 29, 57-69, 1998.

Ansmann, A., Wagner, F., Muller, D., Althausen, D., Herber, A., and Wandinger, U.: European pollution outbreaks during ACE 2: Optical particle properties inferred from multi wavelength lidar and star-Sun photometry, J. Geophys. Res., 107(D15), 4259, doi:10.1029/2001JD001109, 2002.

Derimian, Y., Karnieli, A., Kaufmann, Y. J., Andreae, M. O., Andreae, T. W., Dubovik, O., Maenhaut, W., Koren, I., and Holben, B. N.: Dust and pollution aerosols over the Negev desert, Israel: Properties, transport and radiative effect, J. Geophys. Res., 111, D05205, doi:10.1029/2005JD006549, 2006.

Elias, T., Silva, A. M., Belo, N., Pereira, S., Formenti, P., Helas, G., and Wagner, F.: Aerosol extinction in a remote continental region of the Iberian Peninsula during summer, J. Geophys. Res., 111, D14204, doi:10.1029/2005JD006610, 2006.

Gerasopoulos, E., Andreae, M. O., Zerefos, C. S., Andreae, T. W., Balis, D., Formenti, P., Merlet, P., Amiridis, V., and Papastefanou, C.: Climatological aspects of aerosol optical properties in Northern Greece, Atmos. Chem. Phys., 3, 2025-2041, 2003, http://www.atmos-chem-phys.net/3/2025/2003/.

Koren, I., Kaufman, Y. J., Remer, L. A., and Martins, J. V.: Measurement of the Effect of Amazon Smoke on Inhibition of Cloud Formation, Science, www.sciencemag.org, 303, 13421345, 2004.
Lyamani, H. and Alados-Arboledas, L.: Seasonal and diurnal variations of scattering and absorption properties of aerosols in an urban area, Granada, Spain, European Aerosol Conference 2007, Salzburg, Abstract T13A200, 2007.

Pereira, S. N., Wagner, F., and Silva, A. M.: Scattering properties and mass concentration of local and long-range transported aerosols over the South Western Iberian Peninsula, Atmos. Environ., 42, 7623-7631, doi:10.1016/j.atmosenv.2008.06.008, 2008.

Putaud, J.-P., Van Dingenen, R., Baltensperger, U., Brüggemann, E., et al.: A European aerosol phenomenology; physical and chemical characteristics of particulate matter at kerbside, urban, rural and background sites in Europe, European Commission, Report nr. EUR 20411 EN, 2003.

Silva, A. M., Bugalho, M. L., Costa, M. J., von Hoyningen-Huene, W., Schmidt, T., Heintzenberg, J., and Henning, S.: Aerosol optical properties from columnar data during the second Aerosol Characterization Experiment on the south coast of Portugal, J. Geophys. Res., 107(D22), 4642, doi:10.1029/2002JD002196, 2002.

Silva, A. M., Costa, M. J., Wagner, F., Bortoli, D., Pereira, S., Belo, N., Bugalho, L., Alados-Arboledas, L., Lyamani, H., GuerreroRascado, J. L., Kindred, D., and Smith, M.: CAPEX - AEROPOR Overview: Objectives and first results, European Aerosol Conference 2007, Salzburg, Abstract T13A185, 2007.

Vrekoussis, M., Liakakou, E., Koçak, M., Oikonomou, K., Sciare, J., and Mihalopoulos, N.: Seasonal variability of optical properties in the Eastern Mediterranean, Atmos. Environ., 39, 70837094, 2005. 